\title{
Optimizing Synthesis of Citrus limetta Peel Silver Nanocomposites Possessing Larvicidal Potential against Dengue Vector, Aedes aegypti L.
}

\author{
Devina Aggarwal ${ }^{1}$, Aarti Sharma ${ }^{2}$, Sarita Kumar ${ }^{3, *}$ \\ ${ }^{1}$ Department of Science, Modern School, New Delhi, India \\ ${ }^{2}$ Department of Life Sciences (SOS), Indira Gandhi National Open University, New Delhi, India \\ ${ }^{3}$ Department of Zoology, Acharya Narendra Dev College, University of Delhi, New Delhi, India
}

Received October 13, 2019; Revised November 25, 2019; Accepted December 4, 2019

Copyright $\bigcirc 2020$ by authors, all rights reserved. Authors agree that this article remains permanently open access under the terms of the Creative Commons Attribution License 4.0 International License

\begin{abstract}
Aedes aegypti L. is the major vector accountable for the spread of several diseases of medical importance. The control strategies primarily relying on chemical insecticides have caused negative impact on our environment and human health. Thus, current study employed Citrus limetta peel extracts (CLPE) against larvae of Ae. aegypti. Silver nanocomposites (AgNCs) from CLPE were synthesised and the process of synthesis was optimized by varying temperature; volume and concentration of silver nitrate solution; and the volume of catalyst. A conspicuous change in colour of the reaction mixture was noticed from pale yellow to dark brown. This indicated the synthesis of AgNCs which was traced by UV-Visible spectroscopy. The optimum synthesis of CLPE-AgNCs was obtained with the mixture of $4 \mathrm{~mL}$ $\mathrm{AgNO}_{3}(3 \mathrm{mM})$ and $3 \mathrm{~mL}$ CLPE. The larvicidal assay with these nanoparticles against $A$ e. aegypti resulted in $\mathrm{LC}_{50}$ and $\mathrm{LC}_{90}$ values of $26.82 \mu \mathrm{g} / \mathrm{mL}$ and $99.32 \mu \mathrm{g} / \mathrm{mL}$ after $24 \mathrm{~h}$ of exposure; which respectively decreased to $19.51 \mu \mathrm{g} / \mathrm{mL}$ and $71.99 \mu \mathrm{g} / \mathrm{mL}$ after $48 \mathrm{~h}$ of exposure. The results elucidate 1.3-fold higher larvicidal efficacy of nanoparticles with increased duration of larval exposure. We suggest that synthesis of AgNCs by utilizing peel extract of $C$. limetta is a cost-effective and eco-safe alternative to conventional insecticides; and can be utilized as the potent mosquito larvicide.
\end{abstract}

Keywords Green Synthesis, Silver Nanocomposites, Citrus limetta, Larvicidal, Aedes aegypti

\section{Introduction}

Aedes aegypti, the dreadful and global vector of fatal diseases; like Yellow fever, Zika, Dengue fever and Chikungunya; has captivated attention of researchers, health organizations and vector control bodies. In the last few decades, the prevalence of Aedes-borne diseases; especially dengue; has augmented extensively at global level. According to World Health Organization, almost half of the world's population (3.9 billion) residing in 128 countries is prone to the dengue infection while more than 100 countries are endemic to dengue [1]. According to Union Health Ministry of India, the infections and fatalities caused by dengue virus are rising in India year by year raising serious concerns about the vector control.

It has been suggested that the rising dengue cases in India may be because of inappropriate vector control strategies, unplanned urbanization, variable environmental factors, host-pathogen interactions and immunological factors [2]. The radical shift of dengue from urban areas to rural areas is also considered one of the reasons for increase in incidences and severity of disease [3]. Though, Dengvaxia (R), a dengue vaccine, has been formulated and registered in several countries; it has not yet been approved by the Government of India and has recommended more clinical trials [4]. Because of lack of adequate medication and vaccines, the only measure to control the dengue is still based on the vector control.

Various measures have been attempted for Aedes control, yet major strategies still rely upon the use of chemical insecticides despite their harmful effects on the environment and human health. Therefore, researchers are nowadays exploring botanical extracts to formulate an eco-safe and effective remedy. Several botanicals, weeds and fruit wastes have been investigated as mosquito control agents and found effective [5-7]. The fruits, seeds, roots and leaves of the citrus plant have also been examined for their potential as mosquito control agents $[8,9]$. The citrus 
peels are being explored as a safe alternate to synthetic insecticides against mosquitoes as these are nutrients-rich and contain several secondary metabolites. Reports have revealed the larvicidal efficacy of the ethanolic extracts prepared from orange peel (Citrus sinensis) against $A e$. aegypti [10]. The moderate efficacy of hexane leaf extracts of $C$. sinensis has been reported by Warikoo et al. [11] against early fourth instar of Ae. aegypti. They obtained $\mathrm{LC}_{50}$ and $\mathrm{LC}_{90}$ values of 446.84 and $1370.96 \mathrm{ppm}$, respectively, after $24 \mathrm{~h}$ of larvicidal bioassay. Earlier, essential oil from Citrus limon was found effective against larvae of Ae. aegypti, Culex quinquefasciatus and Anopheles stephensi [12]. Our earlier studies have established larvicidal efficacy of hexane and petroleum ether extract of Citrus limetta (Sweet Lime or Mosambi) peels against Ae. aegypti [13]. The study showed $\mathrm{LC}_{50}$ values of $96.15 \mathrm{ppm}$ and $145.50 \mathrm{ppm}$ on $24 \mathrm{~h}$ larval exposure to hexane and petroleum ether extracts, respectively. The present study is an extension to our previous study and is aimed to formulate nanocomposites from $C$. limetta peel extracts, for probable use as more effective agents of mosquito control than crude extracts.

The formulation of nanoparticles (NP) using various agents has received substantial deliberation due to their exclusive features and potential applications in diverse fields [14]. The green synthesis of NPs using various biological agents is preferred over chemical and physical synthesis of NPs and, is considered more consistent, dependable and eco-friendly. This may be attributed to the biodegradable nature of agent used and absence of toxic chemicals. Therefore, utilization of botanicals and their secondary metabolites, such as flavonoids, tannins and ascorbic acid, is preferential for the formulation of NPs. Numerous plants have been investigated for the synthesis of silver nanocomposites; including gwarpatha (Aloe vera), neem (Azadirachta indica), green tea (Camellia sinensis), leguminous shrub (Sesbania drummondii), natural rubber (Hevea brasiliensis), lemongrass (Cymbopogon citratus) and prickly chaff flower (Achyranthes aspera), etc. [7, 15].

A few studies have reported the utilization of citrus fruit extract as an effective, natural, renewable and low-cost bio-reducing agent for the synthesis of silver nanocomposites. Citrus peel represents an economic and cost-effective substrate for green synthesis of silver nanocomposites. It is known to comprise a variety of active constituents; such as vitamin $\mathrm{C}$, flavonoids and poly methoxylated flavones etc.; which are often rare in other plant extracts [16-18]. It has also been reported that Citrus peel yields thousands-fold more phenolic compounds as compared to its pulp extracts.

Thus, keeping in mind the biodegradable nature, cost-efficacy and larvicidal potential of $C$. limetta peel extract against $A$ e. aegypti, the silver nanocomposites were synthesized using the extract. In order to obtain a significant yield, the biosynthetic process was optimized by varying factors; such as concentration and volume of
$\mathrm{AgNO}_{3}$ (substrate), temperature, catalyst etc. The green nano-larvicides thus formed, were assayed against early fourth instar of Ae. aegypti to devise an eco-safe and effective formulation for the control of Ae. aegypti larvae. As $50 \%$ of the annual production of citrus fruits (31 million tons) is peel waste [19], the present study of using Citrus peels as a nano-larvicide against $A$ e. aegypti may be highly significant.

\section{Materials and Methods}

\subsection{Rearing of Aedes aegypti $\mathrm{L}$.}

The present investigations were conducted on the early fourth instars of Ae. aegypti maintained in self-established Insect Pest and Vector Laboratory, Acharya Narendra Dev College (University of Delhi), India. The mosquito was reared under controlled conditions of $28 \pm 1{ }^{\circ} \mathrm{C}, 80 \pm 5 \%$ RH and 14:10 L/ D photoperiod [20].

\subsection{Collection of Citrus limetta Peels and Preparation of Extract}

Fresh and healthy fruits of $C$. limetta were collected from a local market of New Delhi, India. The peels were removed and washed methodically with tap water followed by thorough rinsing in distilled water. The peels were cut into small pieces, weighed using electronic balance (Shimadzu, BL-220H) and ground using an electric blender (Philips, HL-1606). An aqueous extract of $C$. limetta peels was prepared by heating the mixture of $10 \%$ peel extract ( $10 \mathrm{~g}$ of the blended peels in $100 \mathrm{~mL}$ of distilled water) at $60{ }^{\circ} \mathrm{C}$ for $15-20$ minutes [21]. The extract was kept undisturbed for 2-3 hours and filtered twice through Whatman No. 1 filter paper in order to make it particulate-free. In addition, the hexane extract of $C$. limetta was also prepared through cold percolation method [22]. The clear aqueous extract (CLPE) and hexane extract of citrus peels were stored at $4{ }^{\circ} \mathrm{C}$ for further investigations.

\subsection{Synthesis and Optimization of Citrus limetta Silver Nanocomposites}

The $C$. limetta Peel Extract (CLPE) and silver nitrate solutions $\left(\mathrm{AgNO}_{3} ;\right.$ Merck) were combined in different ratios to prepare the nanocomposites. In the mixtures, the volume of CLPE was kept constant $(3 \mathrm{~mL})$ while the volume of silver nitrate was varied $(2,4,8$ and $16 \mathrm{~mL})$. The bio-synthesis was also optimized by varying concentration of silver nitrate ( $1 \mathrm{mM}$ to $5 \mathrm{mM})$, temperature $\left(27{ }^{\circ} \mathrm{C}\right.$, $37^{\circ} \mathrm{C}$ and $\left.60{ }^{\circ} \mathrm{C}\right), \mathrm{pH}$ and catalyst $(\mathrm{NaOH})$. The mixtures were incubated overnight and monitored intermittently to measure the bio-reduction of $\mathrm{Ag}^{+}$. The change in colour of nano-mixture from pale yellow to dark reddish brown served as a primary indicator for the synthesis of 
nanocomposites.

\subsection{UV-Vis Spectroscopy}

The intensity of the nanocomposite mixtures was scanned and recorded in UV-visible spectra using a UV-Vis spectrophotometer (UV-1800, Shimadzu, Japan); in the 200-700 nm wavelength range and $1 \mathrm{~nm}$ resolution. The aqueous solution of $\mathrm{AgNO}_{3}$ was used as control during the spectrophotometry.

The optimal conditions for the biosynthesis of CLPE-mediated silver nanocomposites were selected on the basis of spectral scans. The resultant nano-colloidal solution was centrifuged (twice) at 10,000 rpm for $10 \mathrm{~min}$ in Remi refrigerated Centrifuge to remove any un-interacting biological molecules. The final pellet was collected, dried in a vacuum desiccator, and kept for future investigations.

\subsection{Larvicidal Bioassay against Aedes aegypti}

The standard WHO protocol with a slight modification was followed to estimate the larvicidal potential of the CLPE-AgNCs against the early fourth instars of Ae. aegypti [23]. Different test concentrations, in the range of $25 \mu \mathrm{g} / \mathrm{mL}$ to $200 \mu \mathrm{g} / \mathrm{mL}$, were prepared from the stored pellets of CLPE-AgNCs. A total of 20 active early fourth instars of Ae. aegypti were exposed to $1 \mathrm{~mL}$ of $\mathrm{NCs}$ solution added to $199 \mathrm{~mL}$ of distilled water. Five replicates were conducted simultaneously for each concentration.

Control sets were exposed to the respective concentration of aqueous extract of $C$. limetta and $\mathrm{AgNO}_{3}$ solution. Simultaneous larvicidal bioassays were carried out with hexane extracts of $C$. limetta peels to analyze the larvicidal efficacy obtained with nano-formulations. Larval mortality was recorded after $24 \mathrm{~h}$ and $48 \mathrm{~h}$ of exposure and subjected to statistical analysis.

\subsection{Data Analysis}

The data obtained was analyzed by SPSS Statistical Software Package (Version: 19.0). The lethal concentrations values were recorded at 30,50 and 90 levels. Other statistical parameters including 95\% confidential limits, chi-square, standard deviation and regression coefficient were calculated in order to compute the significance and estimate the difference between test samples.

\section{Results}

Present study attempted the formulation of silver nanocomposites from aqueous peel extract of $C$. limetta and assessed their possible use as a control agent of $A e$. aegypti. Various factors in the reaction mixture were varied and ideal conditions for optimal synthesis were determined. The efficacy of synthesized green nanocomposites was evaluated against early fourth instars of dengue vector $A e$. aegypti.

The incubation of the $C$. limetta peel extract-silver nitrate reaction mixture resulted in a significant colour change of the mixture from light yellowish-green to brown and finally dark brown (Figure 1). The change in the colour of reaction mixture is indicative of the synthesis of NPs which was confirmed by UV-Vis Spectrophotometry.

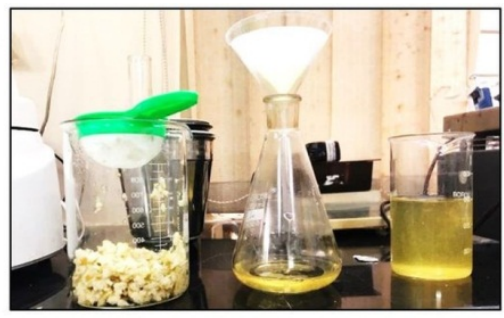

Preparation of Citrus limetta Peel Extract

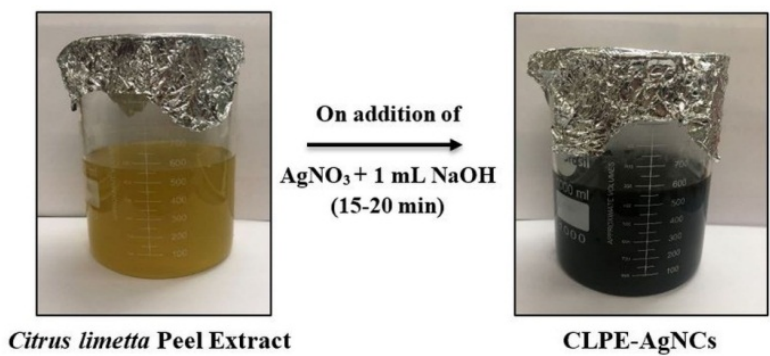

Figure 1. Synthesis of Citrus limetta peel extract-mediated silver nanocomposites depicted by a change in colour from light yellowish-green to dark brown

\subsection{Optimization of CLPE-AgNCs Synthesis: UV-Vis Spectrophotometry}

The synthesis of silver nanocomposites was monitored spectrophotometrically at a wavelength range of 200-700 nm (Figure 2, Table 1). The results showed a shift in the surface plasmon resonance (SPR) band to the higher wavelengths with increase in the volume of silver nitrate in the mixture. 

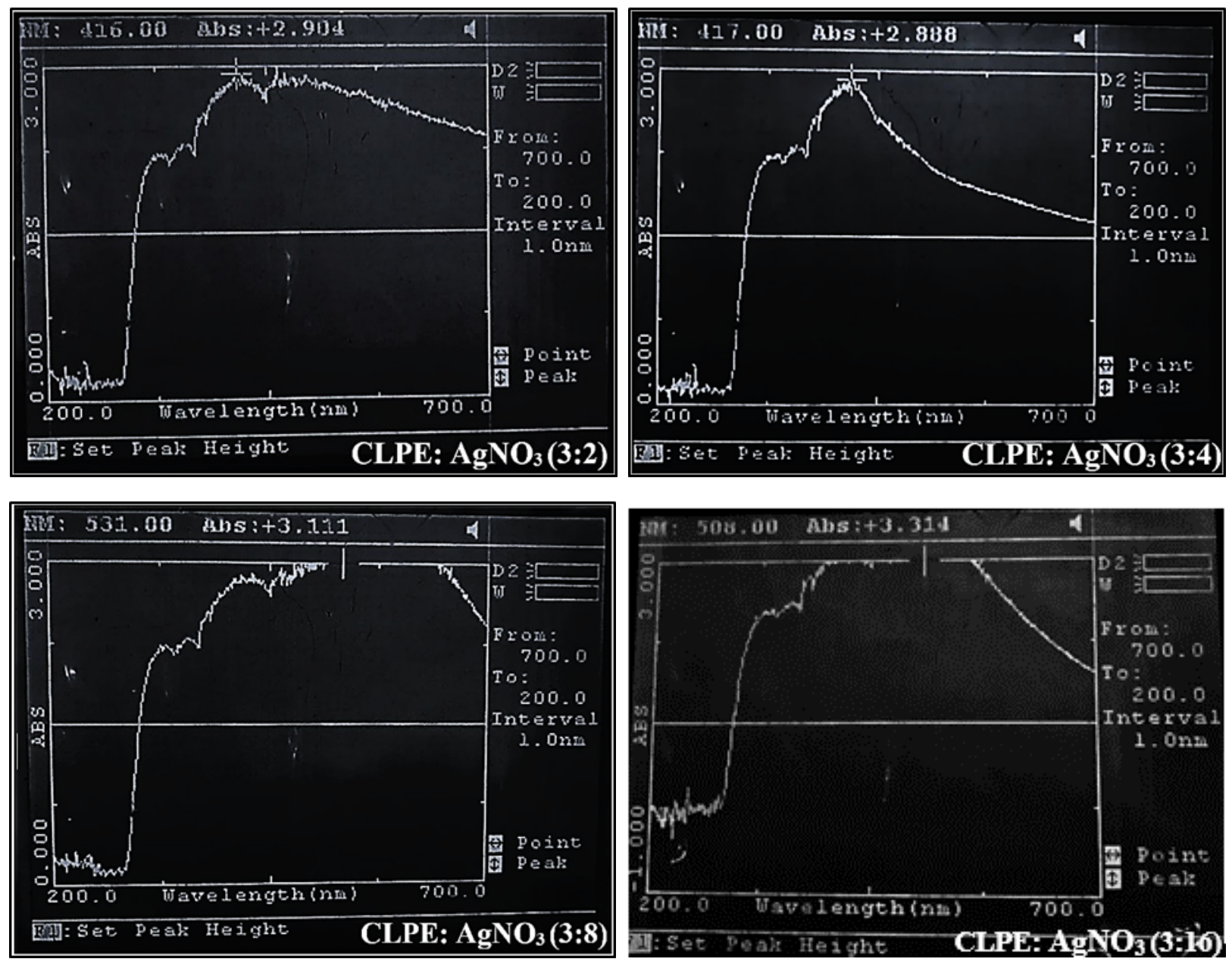

Figure 2. UV-Vis spectra of selected Citrus limetta peel extract-mediated synthesized silver nanocomposites in presence of $1 \mathrm{~mL} \mathrm{NaOH}$ at $60{ }^{\circ} \mathrm{C}$ ); 3 $\mathrm{mL}$ of CLPE with $3 \mathrm{mM}$ silver nitrate of varied volumes; $2 \mathrm{~mL}, 4 \mathrm{~mL}, 8 \mathrm{~mL}$, and $16 \mathrm{~mL}$

Table 1. Optimization of Citrus limetta Peel Extract (CLPE)-mediated synthesis of silver nanocomposites at $60^{\circ} \mathrm{C}$, in presence of $1 \mathrm{~mL} \mathrm{NaOH}$

\begin{tabular}{|c|c|c|c|c|c|c|c|c|c|c|}
\hline \multirow{2}{*}{$\begin{array}{c}\text { CLPE (3mL): different volumes of } \mathrm{AgNO}_{3} \\
\text { solution }(\mathrm{mL})\end{array}$} & \multicolumn{2}{|c|}{$\begin{array}{c}\mathrm{AgNO}_{3} \\
(1 \mathrm{mM})\end{array}$} & \multicolumn{2}{|c|}{$\begin{array}{l}\mathrm{AgNO}_{3} \\
(2 \mathrm{mM})\end{array}$} & \multicolumn{2}{|c|}{$\begin{array}{l}\mathrm{AgNO}_{3} \\
(3 \mathrm{mM})\end{array}$} & \multicolumn{2}{|c|}{$\begin{array}{l}\mathrm{AgNO}_{3} \\
(4 \mathrm{mM})\end{array}$} & \multicolumn{2}{|c|}{$\begin{array}{l}\mathrm{AgNO}_{3} \\
(5 \mathrm{mM})\end{array}$} \\
\hline & $\begin{array}{c}\lambda \\
(\mathbf{n m})\end{array}$ & $\begin{array}{l}\text { Abs. } \\
\text { (a.u) }\end{array}$ & $\begin{array}{c}\lambda \\
(\mathbf{n m})\end{array}$ & $\begin{array}{l}\text { Abs. } \\
\text { (a.u) }\end{array}$ & $\begin{array}{c}\lambda \\
(\mathrm{nm})\end{array}$ & $\begin{array}{l}\text { Abs. } \\
\text { (a.u) }\end{array}$ & $\begin{array}{c}\lambda \\
(\mathbf{n m})\end{array}$ & $\begin{array}{l}\text { Abs. } \\
\text { (a.u) }\end{array}$ & $\begin{array}{c}\lambda \\
(\mathbf{n m})\end{array}$ & $\begin{array}{l}\text { Abs. } \\
\text { (a.u) }\end{array}$ \\
\hline $2 \mathrm{~mL}$ & 408 & 2.982 & 407 & 2.747 & 416 & 2.904 & 374 & 4.095 & 420 & 2.796 \\
\hline $4 \mathrm{~mL}$ & 389 & 2.502 & 402 & 2.608 & 417 & 2.888 & 375 & 4.413 & 371 & 2.382 \\
\hline $8 \mathrm{~mL}$ & 386 & 2.319 & 412 & 2.660 & 531 & 3.111 & 419 & 4.482 & 352 & 2.225 \\
\hline $16 \mathrm{~mL}$ & 395 & 2.502 & 462 & 2.912 & 508 & 3.314 & 330 & 4.280 & 338 & 2.618 \\
\hline
\end{tabular}

As it is clear from the Table 1, the bio-synthesis of silver nanocomposites attempted with $1 \mathrm{mM} \mathrm{AgNO}$ occurred at wavelengths in the range of $386 \mathrm{~nm} \mathrm{-} 408 \mathrm{~nm}$. The nanocomposites synthesized with $2 \mathrm{mM} \mathrm{AgNO}_{3}$ showed the peak in the range of $402 \mathrm{~nm}-462 \mathrm{~nm}$ which reduced to $320 \mathrm{~nm}-420 \mathrm{~nm}$ when $4 \mathrm{mM}$ or $5 \mathrm{mM}$ silver nitrate was added in the reaction mixture. The most optimal wavelength range (416-417 nm) of NPs was observed with the reaction mixture consisting of $3 \mathrm{mM} \mathrm{AgNO}_{3}$.

The optimum biosynthetic combination was further confirmed by the observation of a sharp and narrow absorbance peak in UV-Vis spectra of nanocomposites synthesized with $3 \mathrm{mM} \mathrm{AgNO}$. The results are presented in Fig. 2 which shows the appearance of a noticeable, narrow and conspicuous absorbance peak at $417 \mathrm{~nm}$ with a mixture of $4 \mathrm{~mL}$ silver nitrate and $3 \mathrm{~mL}$ CLPE. The absorbance peaks obtained with other volumes of silver nitrate $(2,8$ and $16 \mathrm{~mL})$ in the reaction mixture were inconspicuous and broader indicating $4 \mathrm{~mL}$ of silver nitrate as the optimum volume.

In addition, varying the reaction temperature; $27^{\circ} \mathrm{C}$, $37{ }^{\circ} \mathrm{C}$ and $60{ }^{\circ} \mathrm{C}$, showed the fastest reaction at $60{ }^{\circ} \mathrm{C}$. Whole process of bioreduction completed within $2 \mathrm{~h}$ at $60{ }^{\circ} \mathrm{C}$ while at lower temperatures; the reaction took $24 \mathrm{~h}$ 
for completion. Furthermore, addition of $\mathrm{NaOH}$ to reactant mixture at $60{ }^{\circ} \mathrm{C}$ increased the rate of reaction by 8 -fold within 15-20 minutes.

\subsection{Evaluation of Larvicidal Efficacy of Citrus limetta Silver Nanocomposites against Aedes aegypti}

The $C$. limetta silver nanocomposites synthesized using the reaction mixture of $3 \mathrm{~mL}$ CLPE: $4 \mathrm{~mL}$ of $\mathrm{AgNO}_{3}$ $(3 \mathrm{mM})$, were evaluated for larvicidal potential against $A e$. aegypti. The results showed effective toxic potential of $C$. limetta peel extract-derived AgNCs against early fourth instars of Ae. aegypti (Table 2, Figure 3). Bioassay with just $25 \mu \mathrm{g} / \mathrm{mL}$ AgNCs resulted in 55\% larval mortality after $24 \mathrm{~h}$, while exposure to $125 \mu \mathrm{g} / \mathrm{mL}$ AgNCs resulted in
95\% larval mortality (Table 2). Larval exposure to nanocomposites for an extended duration of $48 \mathrm{~h}$ increased the larval mortality by 1.3 -fold (Figure 3 ).

The regression analysis of larvicidal data revealed the $\mathrm{LC}_{50}$ and $\mathrm{LC}_{90}$ values of $26.82 \mu \mathrm{g} / \mathrm{mL}$ and $99.32 \mu \mathrm{g} / \mathrm{mL}$, respectively after $24 \mathrm{~h}$ of CLPE-AgNCs exposure to the Aedes larvae (Table 2). It is evident from the data that NPs synthesized from $C$. limetta peels exhibited approximately 2-fold toxic potential than that induced by crude hexane peel extract. In comparison to hexane crude extracts of $C$. limetta, CLPE-AgNCs showed higher larvicidal efficacy, effective at 1.73-fold and 2.03-fold lower $\mathrm{LC}_{50}$ dosage. Moreover, no larval mortality was observed in the control assays, on exposure to the aqueous extract of $C$. limetta and silver nitrate solution.

Table 2. Larvicidal efficacy of CLPE- AgNCs against early fourth instars of Aedes aegypti L.

\begin{tabular}{|c|c|c|c|c|c|c|c|c|}
\hline Exposure Solution & $\begin{array}{c}\mathrm{LC}_{50} \\
(\mu \mathrm{g} / \mathrm{mL})\end{array}$ & $\begin{array}{c}95 \% \\
\text { fiducial } \\
\text { limits } \\
\end{array}$ & $\begin{array}{c}\text { Fold } \\
\text { Efficacy }\end{array}$ & $\begin{array}{c}\mathrm{LC}_{90} \\
(\mu \mathrm{g} / \mathrm{mL})\end{array}$ & $\begin{array}{c}\text { Fold } \\
\text { Efficacy }\end{array}$ & $\begin{array}{c}95 \% \\
\text { fiducial } \\
\text { limit } \\
\end{array}$ & $\begin{array}{c}\text { Chi } \\
\text { Square } \\
\text { (df) }\end{array}$ & Slope \pm SE \\
\hline \multicolumn{9}{|l|}{ After 24 hours of exposure } \\
\hline Control * & - & - & - & - & - & - & - & - \\
\hline $\begin{array}{c}\text { Crude Hexane extract of } \\
\text { C. limetta peels }\end{array}$ & 46.53 & $40.32-52.97$ & 1.0 & 85.37 & 1.0 & $72.89-109.34$ & $\begin{array}{c}4.79 \\
(5)\end{array}$ & $4.47 \pm 0.4$ \\
\hline $\begin{array}{c}\text { C. limetta peels derived } \\
\text { AgNCs }\end{array}$ & 26.82 & $12.80-38.14$ & 1.73 & 99.32 & 1.16 & $74.57-162.50$ & $\begin{array}{c}4.01 \\
(5) \\
\end{array}$ & $2.25 \pm 0.49$ \\
\hline \multicolumn{9}{|l|}{ After 48 hours of exposure } \\
\hline Control * & - & - & - & - & - & - & - & - \\
\hline $\begin{array}{c}\text { Crude Hexane extract of } \\
C \text {. limetta peels }\end{array}$ & 39.57 & $35.22-43.66$ & 1.0 & 61.92 & 1.0 & $54.77-74.83$ & $\begin{array}{c}2.23 \\
(5) \\
\end{array}$ & $6.49 \pm 0.85$ \\
\hline $\begin{array}{c}\text { C. limetta peels derived } \\
\text { AgNCs }\end{array}$ & 19.51 & $6.51-30.21$ & 2.03 & 71.99 & 1.16 & $52.57-114.18$ & $\begin{array}{l}3.282 \\
(5)\end{array}$ & $2.26 \pm 0.56$ \\
\hline
\end{tabular}

*Bioassays were discontinued as no mortality were recorded even at $1000 \mu \mathrm{g} / \mathrm{mL}$, No mortality was observed in the control, LC $\mathrm{C}_{50}-\mathrm{Lethal}^{2}$ Concentration that kills $50 \%$ of the exposed larvae, $\mathrm{LC}_{90}$ - Lethal Concentration that kills $90 \%$ of the exposed larvae, S.E. $=$ Standard Error, $\chi^{2}=$ Chi-square, $\mathrm{df}=$ degree of freedom; Test samples were transformed into log covariant $\left(\log _{10}\right), p>0.05$, level of significance is greater than 0.05 , no heterogeneity factor is used in the calculation of confidence limits, Values are mean of five replicates

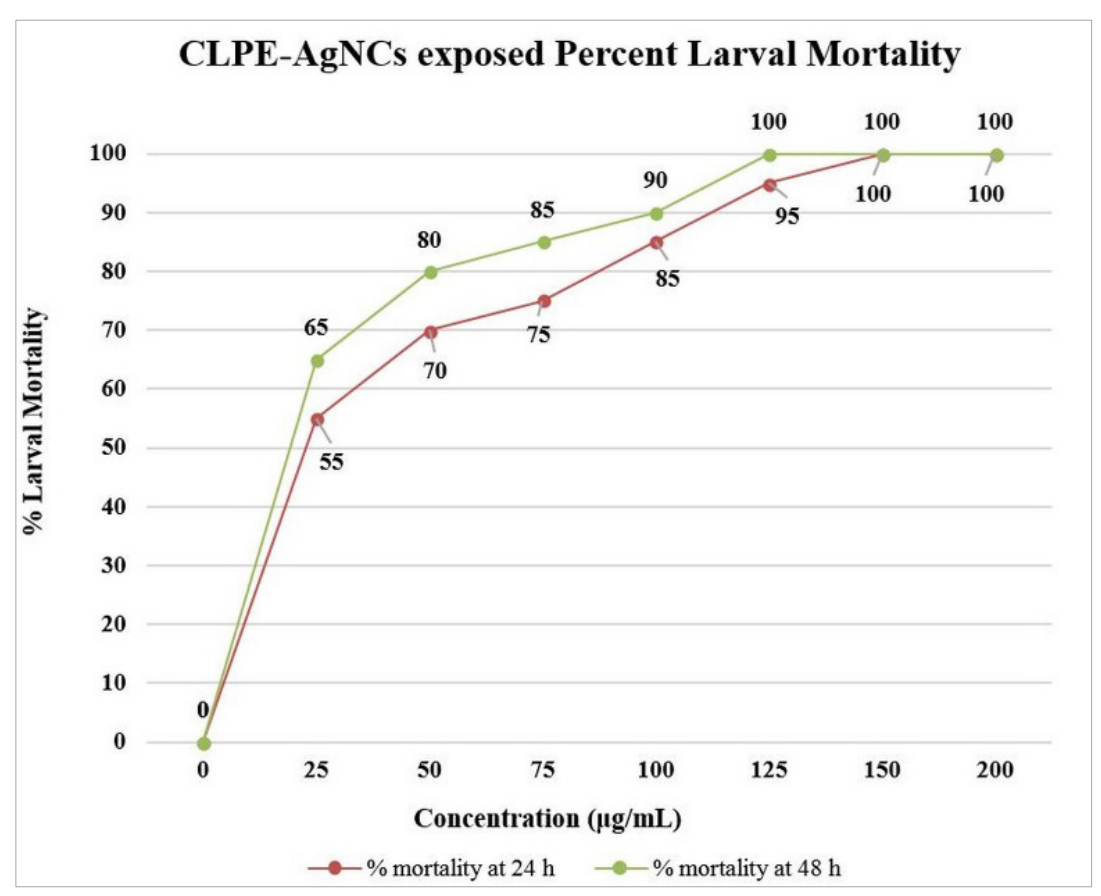

Figure 3. Percent mortality in early fourth instars of Aedes aegypti when exposed to CLPE-AgNCs synthesized with $3 \mathrm{mM} \mathrm{AgNO}_{3}$ 


\section{Discussion}

Rise in Aedes-borne diseases has created worldwide concerns since last few years. Dengue vector, Ae. aegypti, has attracted considerable attention of researchers and vector management organization due to the global occurrence of diseases transmitted by it. Despite multifarious control measures available, control of dengue vector has become a difficult task due to development of resistance to insecticides in use. The harmful effects on the environment and human health caused by the continued increasing doses of insecticides led to exploration of botanical extracts as alternate and eco-safe measures.

Our earlier studies have established the larvicidal efficacy of hexane and petroleum ether extract of $C$. limetta peels against Ae. aegypti [13]. In order to increase its efficiency at much lower concentrations, we attempted to formulate nanocomposites from $C$. limetta peel extracts as a toxic agent against Ae. aegypti. The synthesis of nanocomposites has engrossed extensive consideration due to their inimitable properties and budding applications [24]. Several methods have been attempted for their formulation; however, the green route of synthesis is considered more simplistic, reliable and eco-friendly as compared to the chemical and physical methods. The utilization of environmentally benign resources for the nanocomposites synthesis offers several benefits in pharmaceutical and biomedical applications [25]. Among these, utilization of NPs for their anti-mosquito potential is of great interest.

In the present investigations, the formation of silver nanocomposites in the aqueous solution of $C$. limetta peels was confirmed by visual colour change after 15-20 minutes of incubation at $60{ }^{\circ} \mathrm{C}$. Similar observations have been documented by Trivedi et al. [16] who also recorded comparable colour change from pale yellow to brownish while synthesizing silver nanoparticles from peels of $C$. limetta. It is suggested that while formulation of NPs, change in colour of the reaction mixture is due to the excitation of Surface Plasmon Vibration in the silver nanoparticles which is positively correlated with $\mathrm{AgNO}_{3}$ concentration in the solution $[21,26]$. The current study also showed that a particular combination of high reductant volume, high temperature and high amount of $\mathrm{NaOH}$ led to rapid color change. This abrupt color change was also observed by Sahoo and Kalyan [27] and Trivedi et al. [16].

It is well known now that UV-Visible spectroscopy is a simple and rapid confirmatory technique for the silver nanocomposite synthesis. The absorbance peak values, ranging between 400 to $500 \mathrm{~nm}$ wavelengths, denote the occurrence of silver nanocomposites in the solution and confirm their synthesis [28, 29]. In current study, optimum synthesis of silver nanocomposites in the solution of $C$. limetta peel extracts was observed at a wavelength ranging from 416-417 nm. Earlier, Konwarh et al. [30] had reported the synthesis of green silver nanoparticles using aqueous peel extract of $C$. sinensis at $404 \mathrm{~nm}$; while Nair et al. [31] observed the synthesis at $429 \mathrm{~nm}-432 \mathrm{~nm}$. The absorption peak of silver nanoparticles synthesized from fresh peels of $C$. limetta observed in the range of $390 \mathrm{~nm}-450 \mathrm{~nm}$ by Trivedi et al. [16] is in agreement with our study. In contrast, when Shanmugavadivu and Kuppusamy [32] recorded UV-Vis spectrum of silver nanoparticles synthesized from the fresh peels of Citrus reticulata, they found the surface plasmon broad peak at $466 \mathrm{~nm}$ after $6 \mathrm{~h}$ of incubation; which is much higher than observed by us. Nevertheless, Jalani et al. [33] recorded UV-Vis spectra of synthesized AgNCs from pomelo peel extract (Citrus grandis) and found standard surface plasmon resonance band in the range of $401 \mathrm{~nm}-433 \mathrm{~nm}$.

The rapid green synthesis of AgNCs using $3 \mathrm{~mL}$ of $C$. sinensis peel extract with $40 \mathrm{~mL}$ of $1 \mathrm{mM} \mathrm{AgNO}_{3}$ solution has been shown by Nair et al. [31]. They obtained NPs within a short period of just two minutes; as against present studies in which the fastest NP synthesis was observed with $3 \mathrm{mM}$ silver nitrate solution. Moodley et al. [34] suggested that raising the temperature can enhance the rate of NPs synthesis thus resulting in smaller-sized NPs. We obtained most stable NPs when reaction mixture was heated up to $60{ }^{\circ} \mathrm{C}$, while Nair et al. [31] obtained the best NPs at $80^{\circ} \mathrm{C}$. The variable conditions reported in AgNCs synthesis may be attributed to the bioreducing agent which may possess different bioactive constituents due to species as well as geographical variations.

Earlier reports have shown that citrus peel extracts possess appreciable larvicidal potential against different mosquito vectors. Current investigations revealed $\mathrm{LC}_{50}$ and $\mathrm{LC}_{90}$ values of $46.53 \mu \mathrm{g} / \mathrm{mL}$ and $85.37 \mu \mathrm{g} / \mathrm{mL}$ when $C$. limetta peel extracts were assayed against Ae. aegypti larvae. In contrast, similar larvicidal assays with hexane peel extracts of $C$. limetta and hexane leaf extracts of $C$. sinensis against Ae. aegypti resulted in much higher $\mathrm{LC}_{50}$ and $\mathrm{LC}_{90}$ values of $96.15 \mu \mathrm{g} / \mathrm{mL}$ and $163.27 \mu \mathrm{g} / \mathrm{mL}$; and 446.84 and $1370.96 \mathrm{ppm}$, respectively [11, 16]. The considerable toxicity of ethanol extract of $C$. sinensis peels has been reported by Murugan et al. [35] against each instar of An. stephensi. They obtained respective $\mathrm{LC}_{50}$ values of 182.24, 227.93, 291.69 and 398.00 ppm against I, II, III, IV and $\mathrm{V}$ instar of An. stephensi. Bagavan et al. [36] investigated the chloroform and methanol extracts of $C$. sinensis peels against An. subpictus and $C x$. tritaeniorhynchus and obtained $\mathrm{LC}_{50}$ values of $58.25 \mathrm{ppm}$ and $38.15 \mathrm{ppm}$, respectively; which are in agreement with the values obtained by us. The aqueous extract of $C$. grandis peels was found to be ineffective when assessed against Ae. aegypti larvae as no mortality were recorded at even $1000 \mu \mathrm{g} / \mathrm{mL}$ [37]. On the other hand, aqueous peel extract of $C$. limetta was effective against fourth instars of Cx. quinquefasciatus but at much higher concentration $\left(\mathrm{LC}_{50}=0.08 \%\right)[38]$

The nanoformulations have been shown to exhibit higher larvicidal potential in comparison to hexane crude extracts of citrus peels. In present study, CLPE-AgNCs 
showed 1.73-fold higher larvicidal potential against $A e$. aegypti as compared to crude extracts. In addition, it also exhibited delayed effects with increased efficacy on increased time of exposure against early fourth instars of Ae. aegypti. The citrus peel-derived nanocomposites have not been yet assessed as potential control agent for mosquitoes. This study is first of its kind till date, to our knowledge, though such NPs have been explored for potential use against Escherichia coli, Pseudomonas aeruginosa (Gram-negative), Salmonella typhimurium and Staphylococcus aureus [24, 39]. Nevertheless, our results are in accordance with studies conducted by Sharma et al. [7] who assessed the impact of Achyranthes aspera-mediated silver nanocomposites against early fourth instars of Ae. aegypti and also reported the delayed toxic impact of green silver nanocomposites.

\section{Conclusions}

In the current study, we have optimized the conditions for ideal synthesis of AgNCs. The synthesized CLPE-AgNCs exhibited significant larvicidal potential against early fourth instars of Ae. aegypti. Thus, CLPE-AgNCs, we believe, can be recommended as an eco-friendly nano-larvicide to control mosquito population.

\section{Acknowledgements}

Authors are highly thankful to Principal, Acharya Narendra Dev College, and University of Delhi for providing infrastructure and research facilities.

\section{Conflicts of Interest}

The authors declare that there is no conflict of interest.

\section{REFERENCES}

[1] WHO (World Health Organization), Dengue and severe dengue. Online available: https://www.who.int/news-room/ fact-sheets/detail/dengue-and-severe-dengue, 2019

[2] S. R. Mutheneni, A. P. Morse, C. Caminade, S. M. Upadhyayula. Dengue burden in India: recent trends and importance of climatic parameters, Emerging Microbes and Infections, Vol 6, No. 8, e70

[3] N. Arunachalam, U.S. Murty, L. Kabilan, A. Balasubramanian, V. Thenmozhi, D. Narahari, A. Ravi, K. Satyanarayana (2004). Studies on dengue in rural areas of Kurnool District, Andhra Pradesh, India. Journal of the American Mosquito Control Association, Vol. 20, No. 1: 87-90, 2004
[4] WHO (World Health Organization), Dengue vaccine: WHO position paper. Weekly Epidemiological Record, Vol. 91, No. 30: 349-364, 2016.

[5] S. Kumar, N. Wahab, M. Mishra, R. Warikoo. Evaluation of fifteen local plant species as larvicidal agents against an Indian strain of dengue fever mosquito, Aedes aegypti L. (Diptera: Culicidae). Frontiers in Physiology, Vol. 3, No. 104: 1-6, 2012a.

[6] M.C. Rathy, U. Sajith, C.C. Harilal. Larvicidal efficacy of medicinal plant extracts against the vector mosquito Aedes albopictus. International Journal of Mosquito Research, Vol. 2, No. 2: 80-82, 2015.

[7] A. Sharma, S. Kumar, P. Tripathi. A facile and rapid method for green synthesis of Achyranthes aspera stem extract-mediated silver nanocomposites with cidal potential against Aedes aegypti L. Saudi Journal of Biological Sciences, Vol. 26, No. 4: 698-708, 2017.

[8] A.F. Traboulsi, S. El-Haj, M. Tueni, K. Taoubi, N.A. Nader, A. Mrada. Repellency and toxicity of aromatic plant extracts against the mosquito Culex pipiens molestus (Diptera: Culicidae). Pest Management Science, Vol. 61: 597-604, 2005

[9] W. Akram, H.A.A. Khan, F. Hafeez, H. Bilal, Y.K. Kim, J-J. Lee. Potential of citrus seed extracts against dengue fever mosquito, Aedes albopictus (Skuse) (Culicidae: Diptera). Pakistan Journal of Botany, Vol. 42: 3343-3348, 2010.

[10] A.A. Amusan, A.B. Idowu, F.S. Arowolo. Comparative toxicity effect of bush tea leaves (Hyptis suaveolens) and orange peel (Citrus sinensis) oil extract on larvae of the yellow fever mosquito Aedes aegypti. Tanzania Health Research Bulletin, Vol. 7: 174-178, 2008.

[11] R. Warikoo, A. Ray, J.K. Sandhu, R. Samal, N. Wahab, S. Kumar. Larvicidal and irritant activities of hexane leaf extracts of Citrus sinensis against dengue vector Aedes aegypti L. Asian Pacific Journal of Tropical Biomedicine, Vol. 2, No. 2: 152-155, 2012.

[12] A. Amer, H. Mehlhorn. Persistency of larvicidal effects of plant oil extracts under different storage conditions. Parasitology Research, Vol. 99: 473-477, 2006.

[13] S. Kumar, R. Warikoo, M. Mishra, A. Seth, N. Wahab. Larvicidal efficacy of the Citrus limetta peel extracts against Indian strains of Anopheles stephensi Liston and Aedes aegypti L. Parasitology Research, Vol. 111, No. 1: 173-178, 2012b.

[14] B. Swathy. A review of metallic silver nanoparticles. IOSR Journal of Pharmacy, Vol. 4, No. 7: 38-44, 2014.

[15] K. Vijayaraghavan, K.S.P. Nalini, P.N. Udaya, D. Madhankumar D. Biomimetic synthesis of silver nanoparticles by aqueous extract of Syzygium aromaticum. Colloids and Surfaces B: Biointerfaces, Vol. 75: 33-35, 2012.

[16] P. Trivedi, M. Khandelwal, P. Srivastava. Statistically optimized synthesis of silver nanocubes from peel extracts of Citrus limetta and potential application in waste water treatment. Journal of Microbial and Biochemical Technology, Vol. S4: 004, 2014.

[17] R.R. Gada, U. Padalia. Biosynthesis of silver nanoparticles using citrus fruits. International Journal of Pharma and 
Biosciences, Vol. 8, No. 1: 146-149, 2018.

[18] S. Rafiq, R. Kaul, S.A. Sofi, N. Bashir, F. Nazir, G.A. Nayik. Citrus peel as a source of functional ingredient: A review. Journal of the Saudi Society of Agricultural Sciences, Vol. 17, No. 4: 351-358, 2018.

[19] C.S. Sharma, S. Yadav. Green processes to use extract from citrus peel waste for novel applications (direct polystyrene recycling to natural solvent to source of carbon). Conference proceeding at AIChE Annual Meeting, Available athttps://www.aiche.org/conferences/aiche-annu al-meeting/2017/proceeding/paper/25c-green-processes-us e-extract-citrus-peel-waste-novel-applications-direct-polyst yrene-recycling, 2017

[20] A. Sharma, S. Kumar, P. Tripathi. Effects of Achyranthes aspera extracts on the survival and midgut histo-architecture of Aedes aegypti L. early IV instars. Open Parasitology Journal, Vol. 6: 41-51, 2018.

[21] D. Elumalai, P.K. Kaleena, K. Ashok, A. Suresh, M. Hemavathi. Green synthesis of silver nanoparticles using Achyranthes aspera and its larvicidal activity against three major mosquito vectors. Engineering in Agriculture, Environment and Food, Vol. 9, No. 1: 1-8, 2016.

[22] A. Sharma, S. Kumar, P. Tripathi. Evaluation of the larvicidal efficacy of five indigenous weeds against an Indian strain of dengue vector, Aedes aegypti L. (Diptera: Culicidae). Journal of Parasitology Research, Vol. 2016: $1-8,2016$.

[23] A. Sharma, S. Kumar, P. Tripathi. Impact of Achyranthes aspera leaf and stem extracts on the survival, morphology and behaviour of an Indian strain of Dengue Vector, Aedes aegypti L. (Diptera: Culicidae). Journal of Mosquito Research, Vol. 5, No.7: 1-9, 2015.

[24] M. Reenaa, A.S. Menon. Synthesis of silver nanoparticles from different citrus fruit peels extracts and a comparative analysis on its antibacterial activity. International Journal of Current Microbiology and Applied Sciences, Vol. 6, No. 7: 2358-2365, 2017.

[25] D. Jain, H.K. Daima, S. Kachhwaha, S.L. Kothari. Synthesis of plant-mediated silver nanoparticles using papaya fruit extract and evaluation of their anti-microbial activities. Digest Journal of Nanomaterials and Biostructures, Vol. 4, No. 3: 557-563, 2009.

[26] U.K. Parashar, S.P. Saxena, A. Srivastava). A bio-inspired synthesis of silver nanoparticles. Digest Journal of Nanomaterials and Biostructures, Vol. 4: 159-166, 2009.

[27] P.K. Sahoo, K.S.S. Kalyan. Synthesis of silver nanoparticles using facile wet chemical route. Defence Science Journal, Vol. 59: 447-455, 2009.

[28] A.R. Vilchis-Nestor, V. Sánchez-Mendieta, M.A. Camacho-López, R.M. Gómez-Espinosa, Camacho-M.A. López, J.A. Arenas-Alatorre. Solventless synthesis and optical properties of $\mathrm{Au}$ and $\mathrm{Ag}$ nanoparticles using Camellia sinensis extract. Materials Letters, Vol. 62, No. 17-18: 3103-3105, 2008.

[29] P. Logeswari, S. Silambarasan, J. Abraham. Synthesis of silver nanoparticles using plants extract and analysis of their antimicrobial property. Journal of Saudi Chemical Society, Vol. 19, No. 3: 311-317, 2015.
[30] R. Konwarh, B. Gogoi, R. Philip, M.A. Laskar, N. Karak. Biomimetic preparation of polymer-supported free radical scavenging, cytocompatible and antimicrobial "green" silver nanoparticles using aqueous extract of Citrus sinensis peel. Colloids and Surfaces B: Biointerfaces, Vol. 84, No. 2: 338-345, 2011.

[31] S.S. Nair, S.T. Rizvi, P.D. Anthappan. Optimization of rapid green synthesis of AgNPs using Citrus sinensis peel extract for antibacterial activity. International Journal of Advanced Scientific Research and Management, Vol. 3, No. 8: 274-281, 2018

[32] M. Shanmugavadivu, S. Kuppusamy. Green synthesis of silver nanoparticles using Citrus reticulata fruit peels aqueous extract and their antibacterial activity. International Journal of Advanced Research, Vol. 5, No. 4: 700-708, 2017.

[33] N.S. Jalani, W. Michell, W.E. Lin, S.Z. Hanani, U. Hashim, R. Abdullah. Biosynthesis of silver nanoparticles using Citrus grandis peel extract. Malaysian Journal of Analytical Sciences, Vol. 22, No. 4: 676-683, 2018.

[34] J.S. Moodley, S.B.N. Krishna, K. Pillay, Sershen, P. Govender. Green synthesis of silver nanoparticles from Moringa oleifera leaf extracts and its antimicrobial potential. Advances in Natural Sciences:Nanoscience and Nanotechnology, Vol. 9, No. 015011: 1-9, 2018.

[35] K. Murugan, M.P. Kumar, K. Kovendan, D. Amerasan, J. Subramaniam. Larvicidal, pupicidal, repellent and adulticidal activity of Citrus sinensis orange peel extract against Anopheles stephensi, Aedes aegypti and Culex quinquefasciatus (Diptera: Culicidae). Parasitology Research, Vol. 111, No. 4: 1757-1769, 2012.

[36] A. Bagavan, C. Kamaraj, A.A. Rahuman, G. Elango, A.A. Zahir, G. Pandiyan. Evaluation of larvicidal and nymphicidal potential of plant extracts against Anopheles subpictus Grassi, Culex tritaeniorhynchus Giles and Aphis gossypii Glover. Parasitology Research, Vol. 104: 1109-1117, 2008.

[37] M.S. Manorenjitha, M. Jamil, N. Hashim, L.S. Kiong, Z. Jaal. Toxicity of white flesh Citrus grandis Osbeck fruit peel extracts against Aedes aegypti (Linnaeus) larvae and its effect on non-target organisms. International Journal of Mosquito Research, Vol. 4, No. 4: 49-57, 2017.

[38] S. Mallick, U. Adhikari, A. Rawani, G. Chandra. Phytochemical analyses and larvicidal potentiality of fruit peel extracts of Citrus limetta against filarial vector Culex quinquefasciatus. Journal of Mosquito Research, Vol. 6, No. 22: 1-7, 2016.

[39] S. Kaviya, J. Santhanalakshmi, B. Viswanathan, J. Muthumary, K. Srinivasan. Biosynthesis of silver nanoparticles using Citrus sinensis peel extract and its antibacterial activity. Spectrochimica Acta Part A: Molecular and Biomolecular Spectroscopy, Vol. 79, No. 3: 594-598, 2011. 